\title{
Managing the Patient Evidence Base through Trauma Cases in Military University Hospital of Albania.
}

\section{Rudina Degjoni}

Received: 24 May 2018; Accepted: 30 June 2018; Published online: 20 July 2018: DOI: https://doi.org/10.32391/ajtes.v2i2.17

\footnotetext{
Abstract

Background The level of management of traumatic health care services in Albania as a service of the Military University Hospital in Emergency Care differs in relation to other university hospitals across the country, mainly due to changes in the public health of the population. The article aims to present the management of traumatic patients at the Military Hospital in Albania, providing examples of the number of cases that have been addressed in the spread of this disease as epidemiology in Albania. The literature review and data statistics will be carried out by using the hospital records that will be used for further research in Albania. In addition, there is a study of international reports on Trauma management issues, trauma care and quality in Trauma. Much of the results consider the necessity of adopting a comprehensive traumatic system, focusing on quality management and improving trauma care to increase survival and reduce complications to the wounded. Urban conditions and public health policies are the most important factors in developing and implementing programs to improve emergency trauma care services. The heterogeneity of the population and its geographical distribution, the complexity of road accidents, are challenging factors for quantitative research on trauma management and the effectiveness of its care. Staff training in all areas, combined with the existence of modern vehicles and equipment, means of communication and timely transfer of the ambulance, contribute to the treatment of patients with urgent trauma, life saving and prevention of all types of disabilities.

Keywords. Military University Hospital, health trauma management, information, quality of trauma patients

*Coresponding author: Rudina Degjoni

$\equiv$ E-mail: r.degioni@hotmail.com

${ }^{1}$ Head of Patient Department, The Compulsory of Health Care Insurance Fund of Albania
} 


\section{Introduction}

In Albania, roads are a local public concern and are the main cause of trauma from accidents. Road safety is the goal of national, regional interventions aimed at preventing trauma. (Hughes et al, 1995). Albania, for its bad luck, is far behind the provision of road safety in relation to the EU average, the number of accidents ${ }^{1}$ the number of deaths from car accidents. Road traffic accidents are a consequence of the loss of resources, resources and human resources. At one time, there is a considerable cost to society. This abstract realizes a presentation and assessment of the trend of trauma in Albania, the results of which can be used as a reference guide for designing and evaluating trauma management elements in the country.

\section{Chapter I}

\section{University Hospital of Trauma \& Military Hospital}

In Albania, the Central Military University Hospital is a tertiary hospital which provides a specialized poly trauma health care. The Central Military University Hospital has the university status from the beginning of year $2002^{2}$ The Trauma \& Military Hospital is the only specialized hospital in the country, qualified with the mission "trauma management at the national level". The hospital has specialty basis: Emergency, Surgery, Orthopedics, Neurosurgery, ENT, Ophthalmology and Maxillofacial, ICU, Reconstructive Surgery, Therapy and Rehabilitation services. It has a capacity of 192 beds, but in emergencies, disasters and catastrophes the capacity increases up to 250 beds with 321 people

\footnotetext{
${ }^{1}$ European Commission, Annual Accident Report. European Commission, Directorate General for Transport, June 2016.

${ }^{2}$ Council of Ministers no. 375, date 13.07.2002
}

as staff (81 doctors, 200 nurses, technicians pharmacists, 40 administration \& logistics). In a Military Hospital, the emergency department receives an average of $7-8$ patients with poly trauma every day, of these patients, some present directly and many are referred from other hospitals from the different regions because the hospital is located in a strategic geographic position. It is nearby crucifying the national road north-south, which makes possible the transportation of the wounded in a car accident on time. At the moment various problems are faced in the management of patients with poly trauma. In $\mathrm{EU}^{3}$, road accidents annually lead to the death of more than 40,000 people, while the number of people involved exceeds 1.7 million. The most vulnerable group of people is 14 to 25 years old, where accidents in the streets are the cause of death. The main indicators of road safety in Albania have shown improvement, however, what they are doing in comparison with the EU.

\section{Chapter II}

Trauma cases in Albania: the period of 2010-2017 years

Our study has found a high percentage of admissions for hospital trauma for the period 2010 2017. In order to manage this situation, the number of traumas increases is a reflective and retrospective study of trauma management in the hospital. The studies are pointing to the statistical statistics of the Hospital, reviewing the clinical patient screenings that have been presented to the Emergency

\footnotetext{
${ }^{3}$ Accidents at work statistics, Eurostat Statistics Information, November 2016
} 
Hospital during the last few years. Emergency service has received 335361 emergency patients, from 2010 to $2017.64 \%$ of them have had surgical emergencies and $36 \%$ of them therapeutical urgencies.

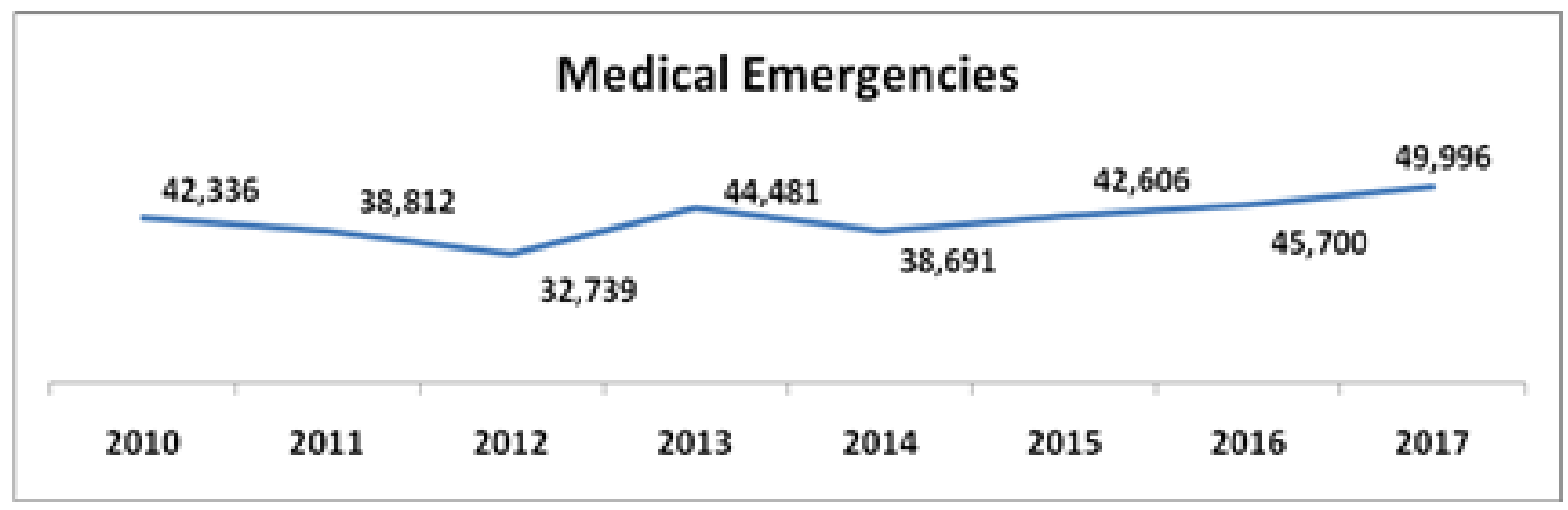

\begin{tabular}{cccc} 
Years & Total & Surgery & Medicine in Emergency \\
\hline 2010 & $42.336(12.62 \%)$ & $24.849(11.58 \%)$ & $17.487(14.49 \%)$ \\
2011 & $38.812(11.57 \%)$ & $22.173(10.33)$ & $16.639(13.79 \%)$ \\
2012 & $32.739(9.76 \%)$ & $19.312(9 \%)$ & $13.427(11.12 \%)$ \\
2013 & $44.481(13.26 \%)$ & $22.100(10.29 \%)$ & $22.381(18.54 \%)$ \\
2014 & $38.691(11.54 \%)$ & $26.847(12.51 \%)$ & $11.844(9.81 \%)$ \\
2015 & $42.606(12.70 \%)$ & $30.392(14.16 \%)$ & $12.214(10.12 \%)$ \\
2016 & $45.700(13.63 \%)$ & $32.334(15.06 \%)$ & $13.366(11.07 \%)$ \\
2017 & $49.996(14.91 \%)$ & $36.661(17.08 \%)$ & $13.334(11.05 \%)$ \\
Total & $335.361(100)$ & $214.668(100)$ & $120.693(100)$ \\
Average & $41.920 \sim 42.000$ & $\sim 27.000$ & $\sim 15.000$
\end{tabular}

Graph 1, Table 1 The medical emergencies (2010 - 2017)

In 2017, there were 103.360 people out of which $62.2 \%$ males, with average age of 54.12 years. A total of $48.65 \%$ are emergency examiners, $46.90 \%$ of Intervention and Microsurgery in Emergency ODS, $4.44 \%$ of patients are treated with daily card (24 hours), with cardiac admissions from hospital emergency to $66.7 \%$ of cases. In most cases, this may be related to a study that would last long. 
However, we do not consider that any day occasion was avoided by the hospital. The average time devoted to the study was on average 30 days, a little higher than expected, due to the high spread of the number of traumas in recent years. It was decided to study $80 \%$ of patients admitted in emergencies for 2017, their diagnosis was identified in all cases treated in emergencies because of $80 \%$ of the total number of patients. According to the census in medical emergencies during the past three years, etiology of trauma in UTMH emergency is (i) car accidents $12 \%$; (ii) gunshot wound $4.8 \%$; (iii) work trauma $38.8 \%$; (iv) wound caused by blind and sharp tools19.4\%. In Albania, the number of deaths by main causes period 2015, 2016, 2017 show that the number of accidents in Albania has been increasing. In 2017, the number of accidents increased by $38.23 \%$ compared to 2016 . The number of deaths in Albanian roads during the period 2000-2017 was $37.1 \%$. However, although there has been a significant increase in the number of deaths, there has been a significant deviation from the goal set in Albania, this can be described as a period that is not used enough to reduce the number of accidents.

\section{Causes of $2015 \quad 2016 \quad 2017$ death}

\begin{tabular}{r|ccc}
\hline Natural & 86,8 & 87,4 & 86,5 \\
Accident & 2,2 & 2,1 & 3,4 \\
Suicide & 1,0 & 1,1 & 1,5 \\
Homicide & 0,4 & 0,4 & 0,4 \\
Accidentwork & 0,3 & 0,2 & 0,2 \\
No & 9,3 & 8,8 & 8,00 \\
information & & &
\end{tabular}

\begin{tabular}{c|ccc} 
Total & $100,0 \quad 100,0 \quad 100,0$
\end{tabular}

Table 2 The percentage of deaths by main causes: 20152016-2017

\begin{tabular}{r|ll} 
Year & Hospitalization & Morbidity \\
\hline 2010 & $7.423(14.94 \%)$ & 2.1 \\
2011 & $6.023(12.11 \%)$ & 2.5 \\
2012 & $5.770(11.62 \%)$ & 2.1 \\
2013 & $4.835(9.73 \%)$ & 2.2 \\
2014 & $5.827(11.72 \%)$ & 2.0 \\
2015 & $5.870(11.81 \%)$ & 3.0 \\
2016 & $6.472(13.02 \%)$ & 2.0 \\
2017 & $7.475(15.04 \%)$ & 2.0 \\
Total & $49.695(100)$ & 2.2 \\
Averag & $6.200 \sim 6.500$ & $\sim 2.2$ \\
$e$ & &
\end{tabular}

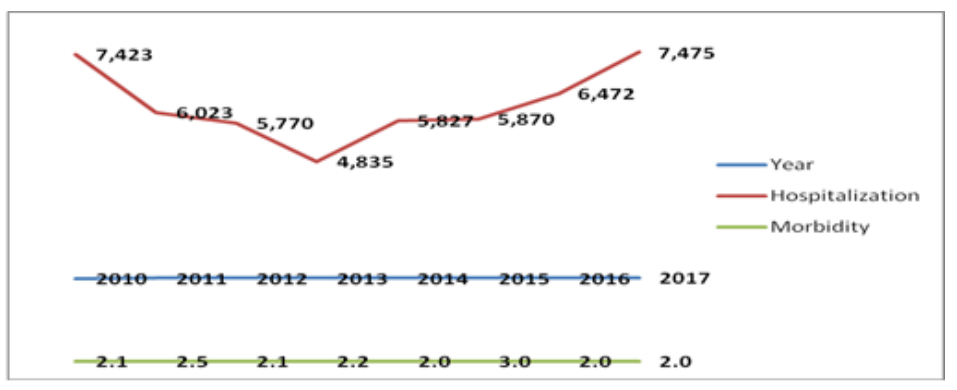

Table 3, Graph 2 The trauma hospitalization by period 2010-2017

It turns out that the mortality is constant while the number of cases hospitalized by Trauma is growing; $13.41 \%$ compared to 2016 . And in the total of the period 2010-2017, their average/1000 is 6,200 patients (2.2 morbidity). 


\begin{tabular}{|lcccccccc|} 
& 2010 & 2011 & 2012 & 2013 & 2014 & 2015 & 2016 & 2017 \\
\hline Hospitalization & 7,423 & 6,023 & 5,770 & 4,835 & 5,827 & 5,971 & 6,620 & 7,475 \\
\hline $\begin{array}{l}\text { Surgery } \\
\text { Hospitalization }\end{array}$ & 5,421 & 4,639 & 4,516 & 4,108 & 5,033 & 5,269 & 5,784 & 6,678 \\
\hline $\begin{array}{l}\text { Trauma in } \\
\text { Total }\end{array}$ & 2,597 & 2,272 & 2,418 & 2,35 & 2,432 & 3,135 & 3,204 & 4,971 \\
\hline $\begin{array}{l}\text { Incidence } \\
\text { (Trauma } \div\end{array}$ & $61,3 \%$ & $58.5 \%$ & $73.8 \%$ & $53 \%$ & $62.8 \%$ & $73.5 \%$ & $70,1 \%$ & $99,4 \%$ \\
Emergency) & & & & & & & & \\
\hline
\end{tabular}

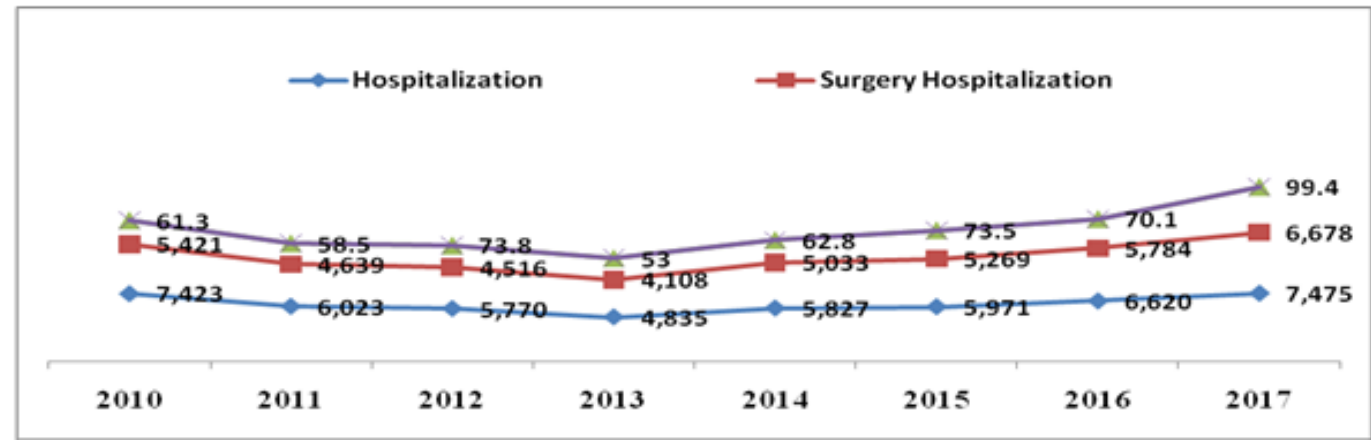

Table 4, Graph 3 The surgery hospitalization and the incidence by period 2010-2017

The incidence of traumas in Albania has been rising considerably by $99.4 \%$ for 2017 , from which 6,678 patients have undergone operational interventions and 7475 patients have been hospitalized. The incidence trend is growing considerably for the country. WHO (2016), estimated that, 1.2 million deaths occurred due to road accidents, 3242 deaths per day and over 20 million injured each year. The World Bank is working closely with the Global Road Safety Facility for the Strategic Plan 2013-2020, this strategic plan sets out how it will contribute to the broader policy. All transport programmers will have a road safety component as it is expected that deaths due to third country road accidents up to 2020, (daly index) (Murray J. et.al. 1996). Traffic accidents do not have the same meaning among them. As far as accidents are concerned, accidents have been classified as: (i) fatal accidents, (ii) light / light injuries, and (iii) accidents with wounds. In Albania, official accidents are registered from the category (i) serious fatalities and (ii) light injuries.

\section{Chapter III}

The management of patient trauma care

According to (Donabedian's theory, 1988) of emergency services, many believe that the "boarding" of emergency patients awaiting inpatient beds compromises quality of care. To assess the quality of care for boarded patients, we used the "structure-process-outcome" framework described 
by (Donabedian, 1988). His three part approach makes quality assessment possible assuming structure (attributes of material or human resources and organizational structure) influences process (what is actually done in giving and receiving care), which influences outcome (health status) (Liu et.al., 2011). To better study the quality of care of boarded patients, one should identify and understand the mechanisms accounting for any potential differences in care three components are identified: (i) the structure (facility - infrastructure and human resources), (ii) the processes (organization, operation, organization and provision of social services), (iii) of actions and services). In the Traumatic Hospital, patients are managed based on organizational activity to reduce the patient's waiting time and to improve the quality of trauma care. This is done in the first contact with the patient, where the first clinical practitioner evaluates, treats, and recommends the patient to other services in a safe manner (NSV Health 2012). The provision of quality in the Trauma Hospital implies an assessment of the actual level of services offered and attempts to change them when necessary (Black, 1990). Quality can be measured and the purpose of measurement is (i) confirmation that the full benefits of medical knowledge are successfully applied to the needs of the patients. (ii) maintaining and improving the level of care. (iii) the ongoing assessment with which the profession maintains and defines its standards and remains responsible for the public concerned. (EU, 2016).

\section{Recommendations}

Albania is at risk of spreading traumatic epidemics in the country. Trauma work, car accidents occupy a leading place in the epidemiological profile. For this purpose, the steps of defining the Trauma
Benchmarking model should be considered to clearly identify what needs to be measured, the quality standards for treating trauma patients, and the electronic database with the patient data to be analyzed and to set the performance gap, set the objectives of action plans according to trauma staff specialties, staff training in all areas, combined with the existence of modern vehicles and equipment, the means of communication and timely transfer of the ambulance, contribute to the treatment of patients with urgent trauma, life saving and prevention of all types of disabilities in Albania.

\section{References}

1. Anand S., Hanson K. DALYs: Efficiency Versus Equity. World Development. 1998;26(2):307-10.

2. Barendregt J. J., van Oortmarssen G. J., Vos T., Murray C. J. L. A Generic Model for the Assessment of Disease Epidemiology: The Computational Basis of DisMod II. Population Health Metrics. 2003;1(1):e4. [PMC free article] [PubMed]

3. Baskent University. 2005. Burden of Disease Final Report. Ankara, Turkey: Baskent University and the School of Public Health, Refik Saydam Hygiene Center, Ministry of Health.

4. A Conceptual Model for Assessing Quality of Care for Patients Boarding in the Emergency Department: Structure-ProcessOutcome. Cameron P, Scown P, Campbell D. Managing access block. Aust Health Rev. 2002;25(4):59-68. [PubMed]

5. Chalfin DB, Trzeciak S, Likourezos A, Baumann BM, Dellinger RP. Impact of delayed transfer of critically ill patients 
from the emergency department to the intensive care unit. Crit Care

Med. 2007;35(6):1477-83. [PubMed]

6. Donabedian A. The quality of care. How can it be assessed? JAMA. 1988;260(12):1743-

8. [PubMed]

7. Dickson EW, Anguelov Z, Vetterick D, Eller $A$, Singh S. Use of lean in the emergency department: a case series of 4 hospitals. Ann Emerg Med. 2009;54(4):50410. [PubMed]

8. European Commission, Annual Accident Report. European Commission, Directorate General for Transport, June 2016.

9. European Commission, 2016, Road Safety Statistics: What is behind the figures; March 2017Hughes KM, et al. Am J Emerg Med. (1995), Equestrian related trauma, AJEM Journal, July 1995, Volume 13, Issue 4, Pages 485-487.

10. Murray L. et al., Measuring the Global Burden of Disease and Risk Factors, 19902001

11. McGlynn EA, Asch SM, Adams J, et al. The quality of health care delivered to adults in the United States. N Engl J

Med. 2003;348(26):2635-45. [PubMed]

12. Moloney ED, Bennett K, O'Riordan D, Silke

B. Emergency department census of patients awaiting admission following reorganisation of an admissions process. Emerg Med J. 2006;23(5):3637. [PMC free article][PubMed]

13. McConnell KJ, Richards CF, Daya M, Bernell SL, Weathers CC, Lowe RA. Effect of increased ICU capacity on emergency department length of stay and ambulance diversion. Ann Emerg Med. 2005;45(5):471

14. Liu SW, Thomas SH, Gordon JA, Hamedani AG, Weissman JS. A pilot study examining undesirable events among emergency department-boarded patients awaiting inpatient beds. Ann Emerg Med. 2009;54(3):381-5.[PubMed]

15. Wiler JL, Gentle C, Halfpenny JM, et al. Optimizing emergency department frontendoperations. Ann Emerg Med. 2009;55(2):142-60. [PubMed]

16. Sprivulis $P C$, Da Silva JA, Jacobs IG, Frazer $A R$, Jelinek $G A$. The association between hospital overcrowding and mortality among patients admitted via Western Australian emergency departments. Med J Aust.2006;184(5):208-12. [PubMed]

17. Schull MJ, Vermeulen M, Slaughter $G$, Morrison L, Daly P. Emergency department crowding and thrombolysis delays in acute myocardial infarction. Ann Emerg Med. 2004;44(6):577-85. [PubMed]

18. Shan W. Liu, MD, MPH, Sara J. Singer, PhD, Benjamin C. Sun, MD, MPP, and Carlos A. Camargo, Jr., MD, DrPHPines JM, lyer $\mathrm{S}$, Disbot M, Hollander JE, Shofer FS, Datner EM. The effect of emergency department crowding on patient satisfaction for admitted patients. Acad Emerg Med. 2008;15:825-31. [PubMed]

19. Richardson DB. The access-block effect: relationship between delay to reaching an inpatient bed and inpatient length of stay. Med J Aust. 2002;177(9):4925. [PubMed]

20. Viccellio A, Santora C, Singer AJ, Thode HC, $J r$, Henry MC. The association between transfer of emergency department boarders to inpatient hallways and mortality: a 4-year experience. Ann Emerg Med. 2009;54(4):487-91. [PubMed]

21. NSV Health, 2012, Emergency Department Models of Care July 2012, World Health 
Organization (WHO). Global Status Report on Road Safety 2016: Supporting A decade of action, Geneva: WHO; 2016
22. INSTAT Albania, Ministry of Transportation and Infrastructure, Annual Report on Road Safety, 2013 OECD, Health policies, a list of latest publications, 2015. 